Acta Universitatis Wratislaviensis

No 3726

Anglica Wratislaviensia LIV

Wrocław 2016

DOI: 10.19195/0301-7966.54.12

\title{
Anna Czura \\ University of Wrocław \\ Book Review: \\ Gary Barkhuizen, Phil Benson, Alice Chik, Narrative Inquiry in Language Teaching and Learning Research, New York and London: Routledge, 2014
}

\begin{abstract}
Since the beginning of the twenty-first century, research methodology in the field of language learning and teaching has taken a narrative turn and, consequently, a growing number of empirical studies have employed narrative inquiry methods to investigate different facets of second language acquisition. Narrative inquiry in language teaching and learning research, a volume authored by Gary Barkhuizen, Phil Benson and Alice Chik, aims to provide a concise and practical introduction to different approaches to designing, implementing, analysing and reporting oral, written and multimodal narrative data in studies on second language learners and teachers. In this review I discuss the general relevance of narrative studies in the field and, after a brief summary of the six chapters, I offer a critical analysis of the book's content.
\end{abstract}

Keywords: narrative inquiry methods, research methodology, qualitative methodology, second language acquisition.

The volume Narrative Inquiry in Language Teaching and Learning Research is a tribute to stories - "small" and "big" stories told by language teachers, learners and researchers. By placing people and their narratives at the heart of empirical investigation, the authors present stories as rich sources of insightful information and offer a thorough introduction to narrative inquiry methods in the field of language learning and teaching. As the authors indicate, "narrative inquiry can help us to understand how language teachers and learners organize their experiences and identities and represent them to themselves and to others" (5). Being a part of the qualitative paradigm, narrative inquiry allows researchers to investigate not only the ultimate product, but also the process of language acquisition. Researchers can acquire a deeper understanding of the storytellers' own motivations, attitudes and feelings, reflections, strategy use as well as immediate educational context. 
Even though narrative methods had been applied in the social sciences for decades, they have only recently gained a more prominent position in studies on different facets of language acquisition. Nowadays narrative approaches are used to look into such aspects of language learning and teaching as teacher and learner identity, the experience of teacher education, language learning histories, study abroad experiences, individual differences, learner autonomy and self-regulated learning (Gabryś-Barker 2012; Jackson 2015; Johnson and Golombek 2002; Pavlenko 2007; Pavlenko and Lantolf 2000; Tsui 2007). This list of research areas is by no means exhaustive, and new topics for investigation can be expected to emerge. The popularity of narrative inquiry in the field is reflected in the number of publications devoted to this methodological approach, which include, for instance, a special issue of TESOL Quarterly: Narrative Research in TESOL, edited in 2011 by Gary Barkhuizen, and collections of studies based on narrative data (e.g. Barkhuizen 2013; Kalaja, Menezes and Barcelos 2008). In view of this, the publication of a practical handbook devoted to the methodology of narrative research seemed needed and called-for.

The structure of the volume, which consists of an introduction, six chapters, references and an index, follows the sequence of a research process and, thus, guides the reader from the early stages of research design, through data elicitation and analysis, to the presentation of the research findings. Following the introduction, in which the authors explain the relevance of and rationale for writing a book on narrative research methods, chapter I, "Narrative inquiry in applied linguistics," is devoted to discussing the role of narrative data in the social sciences and analysing the growth in its popularity in research on language learning and teaching. The categories of narrative methods put forward by the authors are illustrated by means of authentic narratives that had been analysed in prior narrative studies conducted worldwide in the field of language education. Since the authors frequently refer to qualitative studies in further parts of the book, this introductory chapter would perhaps benefit from more explicit clarification of the role of narrative inquiry methods in the qualitative research tradition; however, this minor shortcoming does not change the fact that this chapter offers a concise, yet clear and practical introduction to narrative inquiry methods in language acquisition studies.

The next three chapters are devoted to three major approaches to collecting narrative data: oral narratives, written narratives and multimodal narratives. The last element refers to narratives that include not only oral and written texts, but also such text types as illustrations, photographs, films, sounds and hyperlinks. In each chapter, after brief theoretical introductions, in which these three approaches are explicated, the readers can find a wide range of practical tips on the design and implementation of studies that aim at eliciting narrative data. In chapter 2, the authors offer guidelines on designing semi-structured and open interviews, the frequency and duration of data collection as well as oral data transcription. Chapter 3 details contexts in which written narratives can be applied and focuses 
on learner diaries, language learning histories, teacher narratives and narrative frames. Finally, in chapter 4, the authors draw our attention to the areas in research on language learning and teaching that can benefit from multimodal narratives. These include visual elicitation (e.g. through photos and drawings), multimedia and online language learning histories as well as online group discussions. In the case of each chapter, the authors present sample instructions, elicitation prompts and the structure of an exemplary research procedure on the basis of research design adopted in selected narrative studies. Each chapter concludes with a section devoted to problems and ethical issues that researchers need to consider before they embark on these three types of qualitative research. In order to avoid duplication of other publications on research methodology, the authors do not linger on the characteristics of qualitative research, but underline the uniqueness and distinctiveness of narrative inquiry methods.

Undoubtedly the most intriguing, yet rarely employed data elicitation approach is a multimodal narrative. Bearing in mind the growing importance of computer-assisted language learning and the fact that nowadays much of the interaction in the second language takes place online, the inclusion of non-text types of data in research concerning language learners' and teachers' holistic development appears more than justifiable. Moreover, as Nikula and Huhta (2008: 2) indicate, "using photographs to trigger personal narratives is a valuable way of gaining insights into learners' subjective experiences with languages, and of revealing aspects of informal learning", multimodal data may also appear of extreme usefulness in studies on learner and teacher autonomy, language learning strategies and study abroad experiences.

Finally, the last two units, "Data analysis in narrative inquiry" (chapter 5) and "Writing up narrative studies" (chapter 6), provide guidelines on structuring data analysis and presenting research findings. In chapter 5 the authors discuss content analysis and discourse analysis as two distinctive approaches to studying narrative data. Whereas the former consists in identifying emerging themes in the text, the latter may attend to such discursive elements as metaphors, text structure, and narrative discourse. Chapter 6 starts with a presentation of conventional approaches to research design and reporting that are commonly applied in theses, dissertations or research articles in the field of language education. The authors do not criticise such a traditional structure of reporting, but try to encourage researchers to innovate and exploit narrative data from a more creative angle. Dörnyei (2007) notes that since the presentation of qualitative data may include long stretches of narratives as well as researchers comments of various length and frequency, reading such a report may appear a daunting experience to the reader. Therefore, as the authors highlight, in the process of reporting narrative data it is essential that the researchers think not only about the topic and contents, but also about the potential audience - their needs, interests and professional background. For this reason, to encourage experimentation, the volume presents an array of alternative 
patterns that can be applied to prepare a report on narrative data in various types of theses and publications (for instance, "reporting on narrative interaction" and "reporting in narrative form"). Illustrated with authentic examples found in earlier narrative studies, such alternative arrangements of reporting sections are presented in the volume by means of tables and figures, which support the visualisation of the researcher's line of reasoning and the final outline of the report.

In my opinion, the main contribution of this volume is that most theoretical concepts are illustrated with authentic fragments of narrative data analysed in previous empirical studies, which adds to the clarity and credibility of the publication. In total, the volume includes references to 175 publications on language learning and teaching, in which narrative inquiry methods were either applied or analysed from a methodological point of view. The wealth of reliable bibliographic records concerning narrative methods provide the readers with a sound theoretical grounding for using stories in research and, additionally, offers them handy access to a wide repertoire of well-tried research instruments, such as interview questions, narrative prompts and possible outlines of the findings sections.

It is worth underlining that the authors themselves have extensive first-hand experience in using narrative inquiry methods in studies concerning, for instance, learner autonomy, teacher education, identity, study abroad and online language learning. By applying diverse elicitation tools and unconventional approaches to data analysis and reporting in their own studies, they have proven to be experts in adopting experimental and creative approaches to narrative methods. Still, the authors underscore that since narrative methods are extremely versatile and emergent in nature, potential researchers are invited to develop elicitation techniques and approaches to narrative data analysis that go beyond the scope of this book.

Narrative inquiry is traditionally associated with analysing lengthy oral or written retrospective accounts, which take the form of autobiographies and life stories produced by the subjects of the research. What lends additional value to the volume under review is that it does not dismiss the importance of what Bamberg (2006) refers to as "small stories", i.e. short narratives that reflect the speaker's everyday life and include incidents, commentaries or even fleeting, seemingly unimportant, experiences collected in interactive settings. Such stories may consist in accounts of past critical incidents as well as tellings of ongoing and hypothetical situations. Consequently, the authors of the volume invite us to explore not only the fully-fledged narratives traditionally used in qualitative research, but also their shorter, notoriously under-represented alternatives.

On the book cover, the authors refer to the volume as to an "entry-level introduction to narrative inquiry methods" and I am convinced its merits will be appreciated by undergraduate, graduate and doctoral students, who wish to include stories of language learning or teaching in their research. However, since on many occasions the authors make explicit references to different features of quantitative and qualitative paradigms, potential readers would be advised to possess at least 
rudimentary knowledge of research methodology. Experienced scholars, on the other hand, will appreciate the clear categorisation of narrative research methods and the wealth of direct references to methodological publications and empirical studies that comprise distinctive types of narrative analysis. Finally, the book may even prove to be inspirational for teacher educators who wish to encourage preand/or in-service teachers to produce and analyse their own narrative stories to gain a more in-depth understanding of the development of their teaching competences. In my final comment, on a slightly lighter note, I would like to issue a little warning - the reading of this volume may actually be more time-consuming than one might expect based on the number of pages. The descriptions of the earlier narrative studies are compelling enough to prompt potential readers to refer back to the original publications.

\section{References}

Bamberg, M. 2006. "Stories: Big or small: Why do we care?” Narrative Inquiry 16.1. 139-147.

Barkhuizen, G. (ed.). 2011. Narrative Research in TESOL. Special Issue of TESOL Quarterly 45.3.

Barkhuizen, G. (ed.). 2013. Narrative Research in Applied Linguistics. Cambridge: Cambridge University Press.

Dörnyei, Z. 2007. Research Methods in Applied Linguistics. Oxford: Oxford University Press.

Gabryś-Barker, D. 2012. Reflectivity in Pre-service Teacher Education. A Survey of Theory and practice. Katowice: University of Silesia Press.

Jackson, J. 2015. "Becoming interculturally competent: Theory to practice in international education." International Journal of Intercultural Relations 48. 91-107.

Johnson, K.E. and P. Golombek (eds.). 2002. Teachers' Narrative Inquiry as Professional Development. New York: Cambridge University Press.

Kalaja, P., V. Menezes and A.M.F. Barcelos (eds). 2008. Narratives of Learning and Teaching EFL. Palgrave Macmillan.

Nikula, T. and A.P. Huhta. 2008. "Using Photographs to Access Stories of Learning English." In: Kalaja, P., V. Menezes and A.M.F. Barcelos (eds.) Narratives of Learning and Teaching EFL. Palgrave Macmillan, 171-185.

Pavlenko, A. 2007. "Autobiographic narratives as data in applied linguistics." Applied Linguistics 28. $163-188$.

Pavlenko, A. and J.P. Lantolf. 2000. "Second Language Learning as Participation and the (Re) construction of Selves." In: Lantolf, J.P. (ed.) Sociocultural Theory and Second Language Learning. Oxford: Oxford University Press, 155-177.

Tsui, A.B.M. 2007. "Complexities of identity formation: A narrative inquiry of an EFL teacher." TESOL Quarterly 41. 657-680. 